\title{
Out-of-hours workload among Norwegian general practitioners - an observational study
}

Ingrid Keilegavlen Rebnord ${ }^{1 *}$ (D) Tone Morken ${ }^{1}$, Kjell Maartmann-Moe ${ }^{2}$ and Steinar Hunskaar ${ }^{1,3}$

\begin{abstract}
Background: Repeated studies of working hours among Norwegian regular general practitioners (RGPS) have shown that the average total number of weekly working hours has remained unchanged since 1994 and up until 2014. For both male and female RGPs, the mean total weekly working hours amounted to almost $50 \mathrm{~h}$ in 2014. In recent years, Norwegian RGPs have become increasingly dissatisfied. They experience significantly increased workload without compensation in the form of more doctors or better payment. A study from the Norwegian Directorate of Health in 2018 (the RGP study) showed that Norwegian RGPs worked $55.6 \mathrm{~h}$ weekly (median 52.5). $25 \%$ of the respondents worked more than $62.2 \mathrm{~h}$ weekly.

Based on data from the RGP study we investigated Norwegian RGP's out-of-hours (OOH) work, how the working time was distributed, and to what extent the $\mathrm{OOH}$ work affected the regular working hours.

Methods: In early 2018, an electronic survey was sent to all 4640 RGPs in Norway. Each RGP reported how many minutes that were spent that particular day on various tasks during seven consecutive days. Working time also included additional tasks in the municipality, other professional medical work and $\mathrm{OOH}$ primary health care. Differences were analysed by independent t-tests, and regression analyses.
\end{abstract}

Results: One thousand eighty hundred seventy-six RGPs (40.4\%) responded, 640 (34.1\%) had registered OOH work. Male RGPs worked on average $1.5 \mathrm{~h}$ more doing regular work than did females ( $p=0.001)$ and on average $2.3 \mathrm{~h}$ more $\mathrm{OOH}$ work than females $(p=0.079)$. RGPs with no $\mathrm{OOH}$ work registered a mean of $1.0 \mathrm{~h}$ more clinical work than RGPs working $\mathrm{OOH}(p=0.043)$. There was a large variation in $\mathrm{OOH}$ working hours. A linear regression analysis showed that male RGPs and RGPs in rural areas had the heaviest $\mathrm{OOH}$ workload.

Conclusions: One in three Norwegian RGPs undertook OOH work during the registration week in the RGP study. $\mathrm{OOH}$ work was done in addition to a sizeable regular workload as an RGP. We found small gender differences. $\mathrm{OOH}$ work was not compensated with reduced regular RGP work.

Keywords: General practice, Family medicine, Out-of-hours medical care, Primary care, Workload, Survey, Observational study

\footnotetext{
* Correspondence: inre@norceresearch.no

'National Centre for Emergency Primary Health Care, NORCE Norwegian

Research Centre, Aarstadveien 17, NO-5009 Bergen, Norway

Full list of author information is available at the end of the article
}

(c) The Author(s). 2020 Open Access This article is licensed under a Creative Commons Attribution 4.0 International License, which permits use, sharing, adaptation, distribution and reproduction in any medium or format, as long as you give appropriate credit to the original author(s) and the source, provide a link to the Creative Commons licence, and indicate if changes were made. The images or other third party material in this article are included in the article's Creative Commons licence, unless indicated otherwise in a credit line to the material. If material is not included in the article's Creative Commons licence and your intended use is not permitted by statutory regulation or exceeds the permitted use, you will need to obtain permission directly from the copyright holder. To view a copy of this licence, visit http://creativecommons.org/licenses/by/4.0/ The Creative Commons Public Domain Dedication waiver (http://creativecommons.org/publicdomain/zero/1.0/) applies to the data made available in this article, unless otherwise stated in a credit line to the data. 


\section{Background}

In 2001, Norway introduced a list-based medical primary care service for its inhabitants. All residents have an offer to be on the list of a regular general practitioner (RGP). This ensures continuity in the doctor-patient relationship and more equal healthcare services for all inhabitants. The agreement between the RGPs and the municipality involves the responsibility for the patients on the list but also entails an obligation to participate in the municipal emergency out-of-hours $(\mathrm{OOH})$ services [1]. The way this emergency care is organized varies in the different municipalities due to differences in population density and geography. Large variations in the participation of RGPs in $\mathrm{OOH}$ services have been found in previous studies [2-5].

In 2017, approximately $60 \%$ of the RGPs participated in $\mathrm{OOH}$ work. Many of them worked only part of their full obligations $[3,6]$. Older doctors and female doctors in central municipalities participated least. Few doctors did $\mathrm{OOH}$ work after the age of 55 . These trends have been relatively stable over recent years.

A systematic review in 2006 found that factors related to the profession such as task variation, contact and relationships with colleagues and teaching students often increased job satisfaction On the other hand, employment conditions like low income, too many working hours, administrative burden, and lack of time and recognition were associated with lower job satisfaction [7]. A Norwegian study in 2010 found that the job satisfaction among Norwegian RGPs was high and was rising between 2000 and 2006 [8]. In recent years, increasing dissatisfaction with the workload has been reported among RGPs $[9,10]$. The Care Coordination Reform has gradually been implemented since 2012 [11]. This reform aims to improve the collaboration and coordination between primary and secondary health care. The municipalities were supposed to take the responsibility for more patients, avoid referrals to hospital and receive patients from the hospitals at an earlier stage. Each RGP got increased responsibility for the management of each patient but was supposed to be responsible for fewer patients. However, the increase in the number of RGPs has been much lower than anticipated, and fewer additional resources have been added to the scheme [12, 13].

Repeated studies on Norwegian doctors' working hours showed that, for most doctors, total weekly working hours remained unchanged from 1994 until 2014 [14]. In 2014, the mean number of total working hours was 49.2 among male RGPs and 48.1 among females.

In recent years, there has been an outcry of dissatisfaction among Norwegian RGPs. They experience significantly increased workload without compensation in the form of more doctors or better payment. A study from the Norwegian Directorate of Health in 2018 (the RGP study) showed that Norwegian RGPs on average worked
$55.6 \mathrm{~h}$ weekly (median 52.5), and $25 \%$ worked more than 62.2 h weekly $[15,16]$.

Based on data from the RGP-study [15] we further investigated the characteristics of RGPs' working $\mathrm{OOH}$, the distribution of $\mathrm{OOH}$ work, how $\mathrm{OOH}$ work affects the regular working hours, and several characteristics of RGPs a heavy OOH workload.

\section{Method}

In January 2018, an electronic survey was sent by email to all available RGPs $(n=4640)$ in Norway. The aim was to monitor working hours of RGPs as precisely as possible for one week. The mailing list was based on addresses from Norwegian Healthnet (NHN) and The Norwegian Health Economics Administration (HELFO). Non-responders got reminder emails one and two weeks after the first email was dispatched. In addition to the invitation email, The Norwegian Directorate of Health sent information about the study to all municipalities, and The Norwegian Medical Association sent information to all their RGP members to encourage participation in the study. The study protocol was submitted to and approved by the Ombudsman for Research, Norwegian Centre for Research Data (NSD).

\section{Survey instrument}

The authors designed the questionnaire in Qualtrics software (version 2018 of Qualtrics, copyright@ 2018, Provo, UT), and pilot tested it on 30 RGPs. The questionnaire included the following items: Gender, age, whether the participant was an approved specialist in general practice or not, number of days per week in clinical daytime practice, number of years working as a RGP, employment position, number of inhabitants on their RGP list, number of inhabitants in the municipality, and travel distance to the nearest hospital. For each of seven consecutive days, the RGP was to register how many minutes per day they spent on various tasks in the RGP practice and the time spent for additional positions in the municipality or other positions. The doctors were also to register how many hours they spent on duty at the $\mathrm{OOH}$ services each day during that week.

We asked about three different types of OOH-work: (1) Working at an $\mathrm{OOH}$ clinic, which means that the doctor is present at the clinic throughout the working hours. This kind of duty is common in cities and intermunicipal cooperatives (2); Duty from home parts of the day while responding with turnouts immediately upon urgent inquiries and doing home visits or office consultations when appropriate. This is common in more rural areas with only one GP on duty (3); Being the second doctor on call as support for less experienced doctors or locums. Most inquiries are solved by telephone. This kind of duty is considered less demanding than the two 
others. Hence, we excluded hours from the third category in some analyses.

"Clinical work" is daytime clinical practice work related to the patient list measured in hours per week. "Regular working hours" is defined as all clinical work, additional work for the municipality or other positions, administration of practice and teaching. "Total working hours" is defined as $\mathrm{OOH}$ work in addition to regular working hours.

\section{Statistical analyses}

Descriptive statistics were used, given as mean, median and proportions. To identify differences between groups, independent $\mathrm{t}$-tests and multiple regression analyses were used. Cohen's $d$ (standardized mean difference) was used to measure the effect size between the means. In general: Cohen's $d$-value of 0.8 is defined as large effect, 0.5 is medium effect and 0.2 is small effect. Cohen's $d$ of 1 indicates that the two groups differ by 1 standard deviation; a $d$ of 0.5 indicates they differ by 0.5 standard deviations, and so on. A multiple linear regression analysis was performed to identify factors associated with heavy $\mathrm{OOH}$ workload. Different models for selection of variables were tested but we found no differences in R-square between the models, and therefore a stepwise selection was chosen. The level of statistical significance was set at $p=$ 0.05 . The statistical analyses were performed in IBM SPSS Statistics, version 25 .

\section{Results}

The response rate was $40.4 \%$ (1876 RGPs). A total of 640 RGPs (34.1\%) had also registered work OOH during their registration week.

\section{Characteristics of all RGPs}

$48.5 \%$ of all respondents were females, compared to $42.0 \%$ in the total national RGP population. Mean total working time per week amounted to $55.6 \mathrm{~h}$. Male RGPs worked $57.2 \mathrm{~h}$ while females worked $53.9 \mathrm{~h}(p<0.001)$ and Cohen's $d$ was 0.16 . The difference between male and female RGPs regular work at daytime was $1.5 \mathrm{~h}$ per week $(\mathrm{p}<0.001)$ and Cohen's $d$ was 0.12 .

\section{Distribution of the $\mathrm{OOH}$ working hours}

Table 1 shows the distribution of the different types of $\mathrm{OOH}$ work. The main proportion of the RGPs (79.7\%) worked at an $\mathrm{OOH}$-clinic, $24.1 \%$ worked from home and $24.4 \%$ were also on call as a second doctor. Only $8.8 \%$ (56) of the RGPs had duties as a second doctor on call only. When estimating the total number of $\mathrm{OOH}$ working hours, we excluded the hours worked on call as a second doctor. The minimum value of $\mathrm{OOH}$ work was $0.5 \mathrm{~h}$ and the maximum value was $168.0 \mathrm{~h}$ (all hours in the week). The median value for total $\mathrm{OOH}$ working hours was near $10 \mathrm{~h}$.

\section{Characteristics of RGPs working $\mathrm{OOH}$}

Among RGPs working $\mathrm{OOH}$, the proportion of males was higher than females (37\% vs. 31\%). Male RGPs worked on mean average $2.3 \mathrm{~h}$ more per week than female RGPs with $\mathrm{OOH}$ work but this difference was not significant ( $p=0.079)$ and the effect size Cohen's $d$ was 0.15.

In bivariate analysis, the proportion of specialists, older and more experienced RGPs was lower among RGPs working $\mathrm{OOH}$ (Table 2). There was also a larger proportion of RGPs working $\mathrm{OOH}$ in small municipalities with longer distances to the nearest hospital. Larger list size also seemed to negatively affect participation; the same was found for the participants who were self-employed RGPs.

A multiple logistic regression analysis showed which RGP characteristics were associated with participation in $\mathrm{OOH}$ work. Being a male RGP, long driving distance to the nearest hospital and salaried employment with a bonus agreement were all significantly associated with more $\mathrm{OOH}$ work (Table 3 ). Age more than 54 years and working in cities with more than 100,000 inhabitants were associated with less participation in $\mathrm{OOH}$ work.

Table 1 Distribution of different types of $\mathrm{OOH}$ work

\begin{tabular}{|c|c|c|c|c|c|}
\hline & & $\begin{array}{l}\text { Work at the OOH-clinic } \\
(n=510) \\
\text { Hours }\end{array}$ & $\begin{array}{l}\text { OOH work on duty } \\
\text { from home } \\
(n=154) \\
\text { Hours }\end{array}$ & $\begin{array}{l}\text { OOH work as second } \\
\text { doctor on call } \\
(n=156) \\
\text { Hours }\end{array}$ & $\begin{array}{l}\text { Total OOH work, hours } \\
\text { as second doctor excluded } \\
(n=584) \\
\text { Hours }\end{array}$ \\
\hline All (mean) & & 11.4 & 19.7 & 23.1 & 15.2 \\
\hline Male & & 12.0 & 22.0 & 23.1 & 16.2 \\
\hline Female & & 10.7 & 16.5 & 22.5 & 13.8 \\
\hline \multirow[t]{5}{*}{ Percentiles } & 10 & 6.0 & 2.0 & 5.0 & 6.0 \\
\hline & 25 & 7.0 & 6.5 & 8.0 & 7.3 \\
\hline & 50 & 8.8 & 12.5 & 15.0 & 9.8 \\
\hline & 75 & 15.0 & 23.0 & 15.0 & 16.8 \\
\hline & 90 & 20.2 & 48.0 & 20.2 & 28.1 \\
\hline
\end{tabular}


Table 2 Distribution of characteristics of RGPs working $\mathrm{OOH}$ and not $\mathrm{OOH} . \mathrm{N}=1876$

\begin{tabular}{|c|c|c|c|c|}
\hline Variables & Number & $\begin{array}{l}\text { RGPs not working } \\
\text { OOH }(n=1236) \\
\%\end{array}$ & $\begin{array}{l}\text { RGPs working } \mathrm{OOH} \\
(n=640) \\
\%\end{array}$ & $P$ value \\
\hline Gender & & & & 0.005 \\
\hline Female & 910 & 51.0 & 44.2 & \\
\hline Male & 959 & 49.0 & 55.8 & \\
\hline Specialist in general practice & & & & $<0.001$ \\
\hline Yes & 1267 & 74.6 & 55.3 & \\
\hline No & 596 & 25.4 & 44.7 & \\
\hline Experience (number of years as RGP) & & & & $<0.001$ \\
\hline $0-2$ & 225 & 9.2 & 18.1 & \\
\hline $3-5$ & 273 & 10.2 & 23.8 & \\
\hline $6-10$ & 354 & 17.4 & 22.7 & \\
\hline $11-15$ & 233 & 12.0 & 13.8 & \\
\hline $16-25$ & 330 & 20.2 & 13.3 & \\
\hline$>25$ & 430 & 31.0 & 8.3 & \\
\hline Age & & & & $<0.001$ \\
\hline$<35$ & 263 & 10.6 & 23.0 & \\
\hline $35-44$ & 690 & 30.4 & 50.0 & \\
\hline $45-54$ & 390 & 21.4 & 20.0 & \\
\hline$>54$ & 518 & 37.6 & 9.0 & \\
\hline Number of patients on their list & & & & $<0.001$ \\
\hline$<600$ & 72 & 3.5 & 4.6 & \\
\hline $601-900$ & 316 & 14.3 & 22.3 & \\
\hline $901-1200$ & 721 & 35.8 & 44.5 & \\
\hline $1201-1500$ & 567 & 33.9 & 24.0 & \\
\hline $1501-1800$ & 139 & 9.6 & 3.5 & \\
\hline$>1800$ & 43 & 2.9 & 1.1 & \\
\hline Number of inhabitants in the municipality & & & & $<0.001$ \\
\hline$<3000$ & 50 & 1.6 & 4.7 & \\
\hline $3001-5000$ & 70 & 2.0 & 7.1 & \\
\hline $5001-10,000$ & 198 & 8.3 & 15.3 & \\
\hline $10,001-25,000$ & 407 & 17.9 & 29.7 & \\
\hline $25,001-50,000$ & 376 & 21.8 & 17.4 & \\
\hline $50,001-100,000$ & 281 & 16.7 & 12.2 & \\
\hline$>100,000$ & 471 & 31.6 & 13.4 & \\
\hline Driving distance to nearest hospital & & & & $<0.001$ \\
\hline$<30 \min$ & 1372 & 81.5 & 58.3 & \\
\hline $30 \mathrm{~min}-1 \mathrm{~h}$ & 338 & 14.5 & 25.1 & \\
\hline $1-2 \mathrm{~h}$ & 115 & 3.1 & 12.2 & \\
\hline$>2 \mathrm{~h}$ & 39 & 0.9 & 4.4 & \\
\hline Employment position & & & & $<0.001$ \\
\hline Self-employed & 1584 & 90.6 & 76.1 & \\
\hline Self-employed with bonus agreement & 192 & 7.1 & 16.6 & \\
\hline Salaried & 45 & 1.6 & 4.0 & \\
\hline Salaried with bonus agreement & 28 & 0.6 & 3.3 & \\
\hline
\end{tabular}


Table 3 Factors associated with working out-of-hours compared to not. Multiple regression analysis. $N=1774$

\begin{tabular}{|c|c|c|c|c|}
\hline \multirow{2}{*}{$\begin{array}{l}\text { Variables } \\
\text { Gender }\end{array}$} & \multirow[t]{2}{*}{ OR } & \multicolumn{2}{|l|}{$95 \% \mathrm{Cl}$} & \multirow[t]{2}{*}{$P$-value } \\
\hline & & & & \\
\hline Male (reference) & 1.00 & & & \\
\hline Female & 0.53 & 0.423 & 0.674 & $<0.001$ \\
\hline \multicolumn{5}{|l|}{ Age } \\
\hline$<35$ (reference) & 1.00 & & & \\
\hline $35-44$ & 1.21 & 0.839 & 1.747 & 0.307 \\
\hline $45-54$ & 0.80 & 0.477 & 1.357 & 0.414 \\
\hline$>54$ & 0.18 & 0.096 & 0.340 & $<0.001$ \\
\hline \multicolumn{5}{|l|}{ Specialist in general practice } \\
\hline Yes (reference) & 1.00 & & & \\
\hline No & 1.07 & 0.777 & 1.484 & 0.665 \\
\hline Experience, number of years as RGP ${ }^{a}$ & 0.97 & 0.931 & 1.001 & 0.057 \\
\hline Number of days in clinical practice per week ${ }^{b}$ & 1.00 & 0.919 & 1.095 & 0.945 \\
\hline \multicolumn{5}{|l|}{ Number of patients at their list } \\
\hline$<600$ (reference) & 1.00 & & & \\
\hline $601-900$ & 1.60 & 0.850 & 3.011 & 0.145 \\
\hline $901-1200$ & 1.68 & 0.897 & 3.156 & 0.105 \\
\hline $1201-1500$ & 1.54 & 0.794 & 3.004 & 0.200 \\
\hline $1501-1800$ & 0.99 & 0.438 & 2.258 & 0.989 \\
\hline$>1800$ & 1.65 & 0.526 & 5.078 & 0.395 \\
\hline \multicolumn{5}{|l|}{ Number of inhabitants in the municipality } \\
\hline <3000 (reference) & 1.00 & & & \\
\hline $3001-5000$ & 1.46 & 0.609 & 3.502 & 0.396 \\
\hline $5001-10,000$ & 0.97 & 0.449 & 2.079 & 0.930 \\
\hline $10,001-25,000$ & 1.25 & 0.575 & 2.696 & 0.578 \\
\hline $25,001-50,000$ & 0.69 & 0.308 & 1.550 & 0.370 \\
\hline $50,001-100,000$ & 0.72 & 0.312 & 1.643 & 0.431 \\
\hline$>100,000$ & 0.41 & 0.177 & 0.932 & 0.033 \\
\hline \multicolumn{5}{|l|}{ Employment position } \\
\hline Self-employed (reference) & 1.00 & & & \\
\hline Self-employed with bonus agreement & 1.25 & 0.818 & 1.898 & 0.305 \\
\hline Salaried & 1.57 & 0.735 & 3.340 & 0.245 \\
\hline Salaried and bonus agreement & 4.06 & 1.320 & 12.461 & 0.014 \\
\hline \multicolumn{5}{|l|}{ Driving distance to nearest hospital } \\
\hline Less than 30 min (reference) & 1.00 & & & \\
\hline $30 \min -1 \mathrm{~h}$ & 1.58 & 1.161 & 2.151 & 0.004 \\
\hline $1-2 \mathrm{~h}$ & 5.01 & 2.881 & 8.714 & $<0.001$ \\
\hline More than $2 \mathrm{~h}$ & 3.09 & 1.317 & 7.237 & 0.010 \\
\hline
\end{tabular}

${ }^{\mathbf{a} C o n t i n u o u s ~ v a r i a b l e ~ p e r ~ y e a r . ~}{ }^{\mathbf{b}}$ Continuous variable per half day, minimum 0.5 and maximum 10

There was no significant difference between the regular daytime work among RGPs working or not working $\mathrm{OOH}$. RGPs working $\mathrm{OOH}$ had $0.7 \mathrm{~h}$ more of regular work during daytime than RGPs not working $\mathrm{OOH}$ $(p=0.471)$. Figure 1 shows a scatterplot of paired values of $\mathrm{OOH}$ working hours by regular working hours.
The difference in hours of clinical work between the RGPs working $\mathrm{OOH}$ and RGPs not working $\mathrm{OOH}$ was small $(1.0 \mathrm{~h}$ per week) but statistically significant $(p=$ $0.043)$. Cohen's $d$ was only 0.10 . The difference was primarily explained by the amount of face-to-face contacts $(0.7 \mathrm{~h}$ more for RGPs with no OOH work, $p=0.030$, Cohen's $d$ 


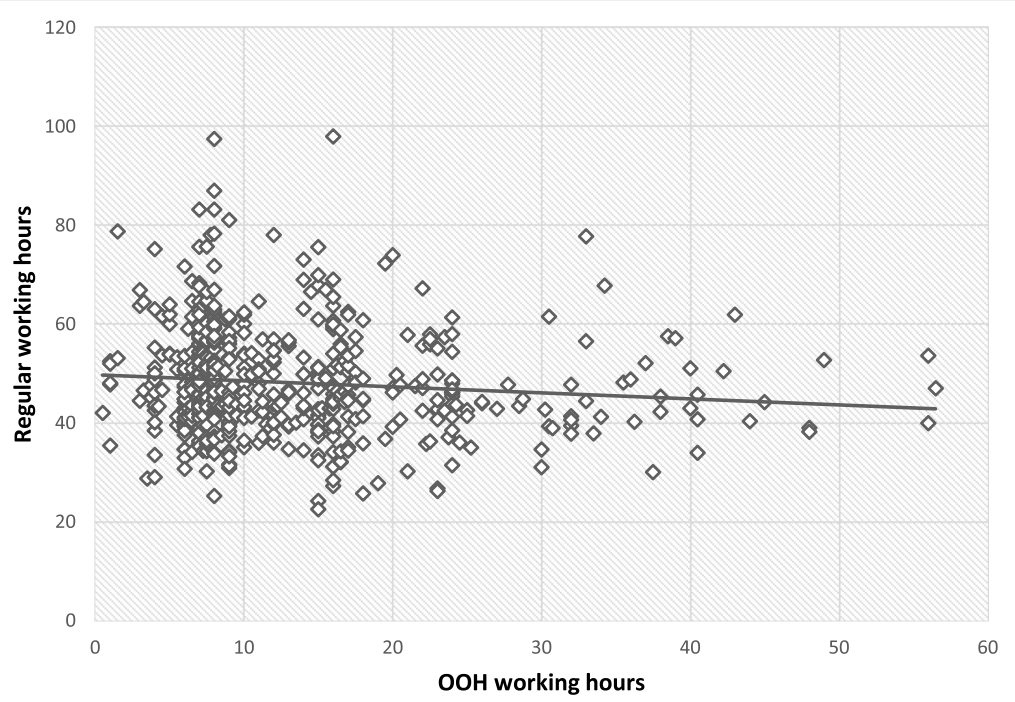

Fig. 1 Comparison of regular working time. Scatterplot of paired regular work and OOH work in hours for RGPs working OOH. $N=567$

0.11) and paper work $(0.7 \mathrm{~h}$ more for RGPs with no $\mathrm{OOH}$ work, $p=0.002$, Cohen's $d$ 0.15). Doctors not working $\mathrm{OOH}$ had $0.1 \mathrm{~h}$ less home visits per week $(p=0.038$, Cohen's $d 0.10)$ and $0.2 \mathrm{~h}$ less meetings per week ( $p=$ 0.003, Cohen's $d$ 0.14).

Figure 2 illustrates the distribution of total working time in quartiles, with $\mathrm{OOH}$ work separated from regular working time. We found that in all quartiles, the differences in regular work between the groups were small; it was the $\mathrm{OOH}$ work that mainly made the difference in the total working hours, both for those with fewer regular working hours as well as for those with a high number of regular working hours.

\section{Factors associated with heavy $\mathrm{OOH}$ workload}

There was a large variation in $\mathrm{OOH}$ working hours especially among those working most. To ascertain variables associated with a high number of working hours $\mathrm{OOH}$, a linear regression analysis was performed with possible explanation variables included (Table 4). A stepwise selection method showed that being a male RGP, working in small municipalities and having a long travelling

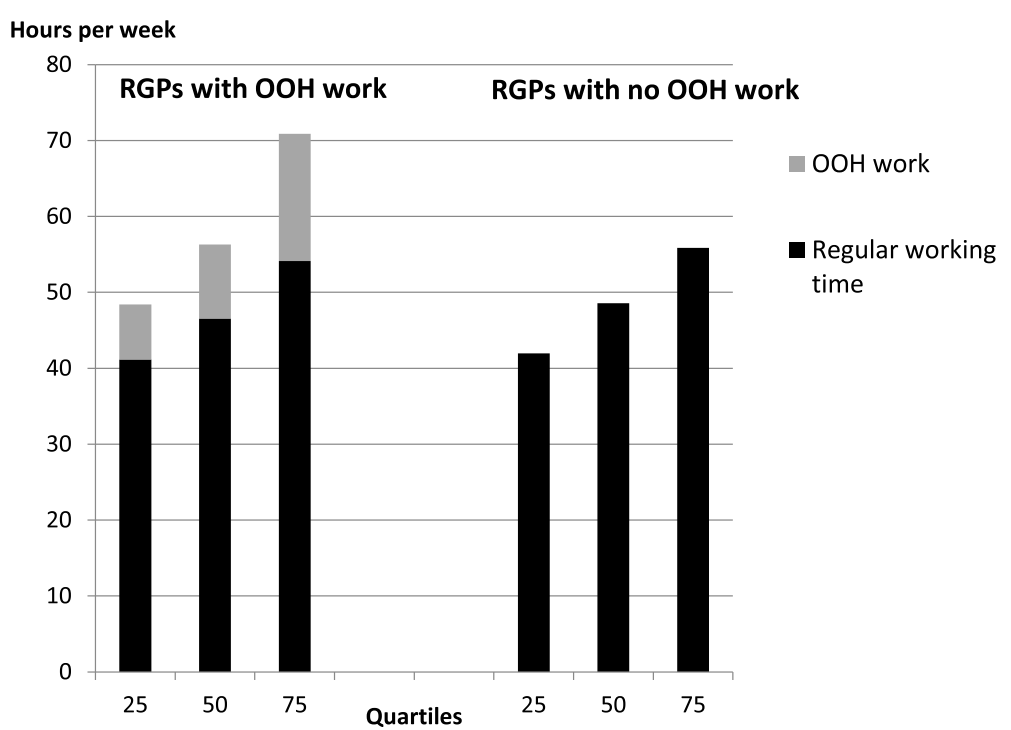

Fig. 2 Comparison of total working time. Comparison of total working time per week between RGPs working or not working OOH in quartiles of total working time. $N=1876$ 
Table 4 Factors associated with heavy workload out-of-hours. $N=573$

\begin{tabular}{llc}
\hline Variables & $\begin{array}{l}\text { Standardized } \\
\text { Beta }(\boldsymbol{\beta})\end{array}$ & $\boldsymbol{P}$-value \\
\hline $\begin{array}{l}\text { Gender } \\
\text { (Male }=0 \text { Female }=1)\end{array}$ & -0.137 & 0.001 \\
$\begin{array}{l}\text { Number of inhabitants in the municipality } \\
\text { (7 categories, ref. Table 1) }\end{array}$ & -0.114 & 0.025 \\
$\begin{array}{l}\text { Driving distance to nearest hospital } \\
\text { (per } 30 \text { min, } 4 \text { categories ref. Table 1) }\end{array}$ & 0.211 & $<0.001$ \\
$\begin{array}{l}\text { Number of patients at their list } \\
\text { (per } 300 \text { patient, 6 categories, ref. Table 1) }\end{array}$ & -0.113 & 0.010 \\
\hline
\end{tabular}

Linear regression analysis of total working hours $\mathrm{OOH}$ exclusive work as second doctor. R square 0.125

distance to nearest hospital were factors associated with more $\mathrm{OOH}$ work per week. Moreover, the RGPs with many hours of $\mathrm{OOH}$ work had shorter patient lists.

\section{Discussion}

During one week in January 2018, every third RGP in Norway was working $\mathrm{OOH}$. $\mathrm{OOH}$ work was done in addition to an already heavy workload as an RGP. RGPs working $\mathrm{OOH}$ has slightly less clinical daytime practice than those not working OOH. Male RGPs and RGPs from rural areas have the heaviest $\mathrm{OOH}$ workload.

\section{Strengths and limitations}

We used an electronic survey because of its clear advantages, e.g. timesaving, cost-effective, no need of data entry. As far as we know, among the Norwegian GPs, all age groups are very well-acquainted with web-based surveys. The response rate of $40.4 \%$ is rather low, with a risk of nonresponse bias. However, compared to other studies among physicians, our response rate on an electronic survey is quite good [17]. Generally, physicians have lower response rates than the general public, and different factors that may increase the rate are found in some reviews and trials $[17,18]$.

The survey was relatively time-consuming to answer since all work-related activity had to be registered continuously for seven consecutive days. The response rate was slightly lower in the oldest age groups. This explains that the female proportion was slightly higher than the national average among RGPs [15]. Despite this small difference, we found our study sample representative with respect to age, gender, list size and proportion of participants who were approved specialists in general practice.

Self-reported working time has some disadvantages. Previous research on RGPs' workload in Norway was also by self-registration but on smaller numbers of RGPs $(n=203)$ and retrospective [14]. The strength of our study is that all RGPs in Norway got an invitation. The potential degree of over- or under-estimation of working hours in this study is not known. There is a possibility that more hard-working RGPs respond compared to those working less, as the latter may feel they should not 'spoil' a desired outcome of heavy workload. On the other hand, experienced RGPs who are used to a heavy workload and those who are comfortable with it may not respond either. $\mathrm{OOH}$ work is easier to register than other work tasks that flow more into each other, as the duties are set up with certain hours and paid per hour. Therefore, we assume that the number of hours $\mathrm{OOH}$ is correct with a relatively high degree of accuracy.

\section{Discussion of results}

In this study, one of three RGPs worked $\mathrm{OOH}$ during one week in January 2018. From other Norwegian studies, we know that more than one third of all RGPs participate in $\mathrm{OOH}$ work. In 2017 around 60\% of RPGs participated but they had fewer contacts than other doctors at $\mathrm{OOH}$-services and therefore probably take fewer duties $[3,6]$. Since our registration was only for one week, there are probably more doctors working $\mathrm{OOH}$ less frequently. These RGPs are probably working in larger an $\mathrm{OOH}$-district where many doctors participate. That is why we reckon that the portion of RGPs working $\mathrm{OOH}$ is lower in our study sample than in the general RGP population. Our study cannot state the total workload of $\mathrm{OOH}$ work for all RGPs but show a mean average for the situation during one normal January week.

Total workload for RGPs is a sum of different tasks. Clinical work associated directly with the patient list is the main task, but $\mathrm{OOH}$ work and additional work for the municipality are also compulsory in Norway. Countries that have the same organization as Norway report significant out-of-hours demand and heavy workload in rural areas $[19,20]$. The mean total number of working hours for RGPs was $7 \mathrm{~h}$ more than found in 2014 [14]. Because of different methods and numbers in the study population, it cannot be concluded that there was an exact increase of $7 \mathrm{~h}$ from 2014 until 2018, but our study shows that an increase in the workload is highly likely. Both studies have $\mathrm{OOH}$ work included in the mean, and in our study, the mean total number of working hours is higher for both RGPs groups, including those not working $\mathrm{OOH}$. The total workload for the average RGP is some 20 $\mathrm{h}$ a week above the recommended working hours in Norway, both for regular work and total work [21].

Mean regular working hours are similar for RGPs both with and without $\mathrm{OOH}$ work. It can be compared with GPs in other countries, for example British GPs, i.e. approximately $49 \mathrm{~h}$ per week but with large variations. Our study showed that for all RGPs the OOH work is in addition to already more than full-time RGP work at daytime. There was no association between number of regular working hours and $\mathrm{OOH}$ working hours, and 
only minimal reduction in mean regular work at daytime for RGPs with $\mathrm{OOH}$ work. There were also minimal differences in time spent on other tasks. This can be explained by the fact that most RGPs have their own personal list and the same duty to work $\mathrm{OOH}$ with minor opportunities for flexibility in taking over the work of colleagues.

The small difference in working time between genders in Norway is remarkable. In the United Kingdom, the difference between male and female GPs is estimated to be $6 \mathrm{~h}$ for regular work [22] and in Netherland to be $8 \mathrm{~h}$ on average [23]. For $\mathrm{OOH}$ work we have not found any comparable literature. Our results show that female RGPs have an almost similar workload as males in daytime practice, the gender difference is somewhat greater for $\mathrm{OOH}(2.3 \mathrm{~h}$ compared to $1.6 \mathrm{~h})$. Significantly fewer females participate in $\mathrm{OOH}$ work. Especially when the duties are taken from home (rural areas), female RGPs participate less than male RGPs. This is in line with what is known about gender differences generally in working life in Norway. A larger proportion of women work parttime, and this includes highly educated women [24].

Age over 55 years exempts RGPs from $\mathrm{OOH}$ work according to the negotiated collective agreement. This fits well with what we found; RGPs above the age of 54 seldom worked $\mathrm{OOH}$. There was a clear tendency that a higher proportion of RGPs in the younger age group participated in $\mathrm{OOH}$ work. This may be desired, or may fulfil a requirement to work $\mathrm{OOH}$ as part of the specialization course for general practitioners, along with a desire for higher income at the start of the career [25].

The employment position was also associated with participation in $\mathrm{OOH}$ work. A higher proportion of salaried GPs or GPs with a bonus agreement participated in $\mathrm{OOH}$ work. For small and/or rural municipalities with heavy $\mathrm{OOH}$ workloads, different bonus agreement may be offered as a recruitment effort and explains why a salaried position with a bonus agreement was significantly associated with having $\mathrm{OOH}$ work.

Different variables were associated with heavy $\mathrm{OOH}$ workload and most of them express different conditions in rural areas. Long travelling time to the nearest hospital and small municipalities are two isolated factors associated with heavy $\mathrm{OOH}$ workload. We also found that the more hours a RGP worked $\mathrm{OOH}$, the greater the portion of home visit duties. Rurality is associated with $\mathrm{OOH}$ home visit duties and shorter patient lists; this is very likely an explanatory factor. We had no information about the centrality of the workplaces. Hence it was not possible to correct for this relationship in the analyses.

To organize emergency primary health care in a rural country such as Norway is challenging, but it is at the same time necessary to provide all citizens with equal health care. Our study has shown that with an increasing workload of regular working hours, there is a risk that fewer RGPs will participate in $\mathrm{OOH}$ work. In districts with optional participation, there will be a risk that the RGP's competence will be lost to the $\mathrm{OOH}$ services. In other districts with mandatory participation in $\mathrm{OOH}$ work, there will be a risk of recruitment problems if workloads become excessive and the proportion of women among younger doctors increases. For responsible authorities who plan to organize the $\mathrm{OOH}$ services, it is important to look at the total workload, so that RGPs are ensured an acceptable total workload in line with other employees who participate in shift work.

\section{Implications for future research}

In this study we investigated self-registered working time during one week. Factors that can provide stability and continuity in primary health care were not mapped. Heavy workload indicates a high risk of unstable physician staffing. With increasing numbers of female medical students, it is necessary to examine what conditions are fundamental to enable newly educated female doctors to thrive and stay in the field of RGPs, especially in rural areas where the $\mathrm{OOH}$ workload is heavy.

\section{Conclusions}

During one week, every third RGP in Norway works $\mathrm{OOH}$ in addition to their work as RGP. RGPs working $\mathrm{OOH}$ do not work less during daytime than RGPs not working $\mathrm{OOH}$. Male RGPs and RGPs from rural areas have the heaviest workload in terms of $\mathrm{OOH}$ work. Gender differences are minimal during daytime but more prevalent during $\mathrm{OOH}$ work.

\section{Supplementary information}

Supplementary information accompanies this paper at https://doi.org/10. 1186/s12913-020-05773-7.

Additional file 1. Qualtrics Survey

Abbreviations

RGP: Regular general practitioner; $\mathrm{OOH}$ : Out-of-hours

\section{Acknowledgements}

We thank all the RGPs who participated in the study. We also want to thank Ole Johan Eikeland for help with statistical analysis of data.

\section{Authors' contributions}

IKR, TM, KM and SH conceived the study and the design. TM and IKR performed the analysis. IKR drafted the article. All authors revised, read and approved the final manuscript.

\section{Funding}

The study was funded by the Ministry of Health and Care Services (HOD), Norway. The funder was not involved in the study design, data interpretation, or reviewing of the manuscript.

Availability of data and materials

The datasets used during the current study are available from the corresponding author on reasonable request. 


\section{Ethics approval and consent to participate}

The study was submitted to and approved by the Ombudsman for Research, Norwegian Centre for Research Data (NSD) (Reference 57262). As the study did not contain any health information about the participants and the research did not include health and disease, there was no need for approval from the ethics committee [26]. The consent from the study participants was obtained by written response to the submitted questionnaire.

\section{Consent for publication}

Not applicable.

\section{Competing interests}

The authors declare that they have no competing interests.

\section{Author details}

${ }^{1}$ National Centre for Emergency Primary Health Care, NORCE Norwegian Research Centre, Aarstadveien 17, NO-5009 Bergen, Norway. ${ }^{2}$ The Norwegian Directorate of Health, Oslo, Norway. ${ }^{3}$ Department of Global Public Health and Primary Care, University of Bergen, Bergen, Norway.

Received: 18 December 2019 Accepted: 29 September 2020

Published online: 14 October 2020

\section{References}

1. Nieber T, Hansen EH, Bondevik GT, Hunskår S, Blinkenberg J, Thesen J, et al. Organization of Norwegian out-of-hours primary health care services. Tidsskr Nor Laegeforen. 2007;127(10):1335-8.

2. Sandvik H, Hunskår S. Reimbursement for out-of-hours work in Norway. Tidsskr Nor Laegeforen. 2007;127(10):1347-50..

3. Sandvik H, Zakariassen E, Hunskår S. Norwegian regular general practitioners' participation in out-of-hours work. Tidsskr Nor Laegeforen. 2007;127(19):2513-6

4. Sandvik H, Hunskår S. Working style among regular general practitioners and other doctors in the out-of-hours services. Tidsskr Nor Laegeforen 2010;130(2):135-8.

5. Hjortdahl M, Zakariassen E, Halvorsen PA. Self reported involvement in emergency medicine among GPs in Norway. Scand J Prim Health Care. 2018;36(2):161-9.

6. Sandvik H, Blinkenberg J. Årsstatistikk fra legevakt 2017. Rapport nr. 2-2018. Nasjonalt kompetansesenter for legevaktmedisin, Uni Research Helse, Bergen. 2018. http://bora.uib.no/handle/1956/17544. Accessed 27 Nov 2019.

7. Van Ham I, Verhoeven AA, Groenier KH, Groothoff JW, De Haan J. Job satisfaction among general practitioners: a systematic literature review. Eur J Gen Pract. 2006;12(4):174-80

8. Aasland OG, Rosta J, Nylenna M. Healthcare reforms and job satisfaction among doctors in Norway. Scand J Public Health. 2010;38(3):253-8.

9. Kjosavik SR. Ongoing recruitment crisis in Norwegian general practice. Scand J Prim Health Care. 2018;36(2):107-8.

10. Rosta J, Aasland OG, Nylenna M. Changes in job satisfaction among doctors in Norway from 2010 to 2017: a study based on repeated surveys. BMJ Open. 2019;9(9):e027891.

11. Samhandlingsreformen - informasjon om ikraftsetting av lov om kommunale helse- og omsorgstjenester. Ministry of Health and Care Services, Oslo. 2011. https://www.regjeringen.no/no/dokumenter/ samhandlingsreformen\%2D\%2D-informasjon-om-ik/id667798/. Accessed 27 Nov 2019

12. Christiansen TW, Sandvik H. Fastlegeordningen forvitrer - hva nå? (The family physician system is crumbling - what now?). Tidsskr Nor Laegeforen. 2017;137:(22).

13. Texmon I. Kortere pasientlister, lengre arbeidsdager? (Shorter patient lists, longer working days?). Statistics Norway. 2018. https://www.ssb.no/helse/ artikler-og-publikasjoner/kortere-pasientlister-lengre-arbeidsdager. Accessed 27 Nov 2019.

14. Rosta J, Aasland OG. Doctors' working hours and time spent on patient care in the period 1994-2014. Tidsskr Nor Laegeforen. 2016;136(16):1355-9.

15. Rebnord IKEO, Hunskår S, Morken T. Fastlegers tidsbruk (investigation of regular GPs working hours). In: report to the Norwegian directorate of health. Bergen: National Centre for Emergency Primary Health Care, Uni Research Health; 2018. https:/www.regjeringen.no/no/dokumenter/ fastlegers-tidsbruk/id2592992/. Accessed 27 Nov 2019.
16. Morken T, Rebnord IK, Maartmann-Moe K, Hunskaar S. Workload in Norwegian general practice 2018 - an observational study. BMC Health Serv Res. 2019;19(1):434.

17. Cunningham $C T$, Quan $H$, Hemmelgarn B, Noseworthy $T$, Beck CA, Dixon $E_{\text {, }}$ et al. Exploring physician specialist response rates to web-based surveys. BMC Med Res Methodol. 2015;15:32.

18. Bratlid D. Doctors' time for working with patients and patients' time with 514 doctors. Tidsskr Nor Laegeforen. 2018;138(2).

19. McGrail MR, Humphreys JS, Joyce CM, Scott A, Kalb G. How do rural GPs' workloads and work activities differ with community size compared with metropolitan practice? Aust J Prim Health. 2012:18(3):228-33.

20. Jakob J, Cohidon C, Cornuz J, Selby K. Participation in medical activities beyond standard consultations by Swiss general practitioners: a crosssectional study. BMC Fam Pract. 2018;19(1):52.

21. Cabrita J. Working time developments - 2011. European Foundation for the improvement of living and working conditions, Dublin. 2012. https://www. eurofound.europa.eu/publications/report/2012/working-timedevelopments-2011\#hd33. Accessed 27 Nov 2019.

22. Gravelle H, Hole AR. The work hours of GPs: survey of English GPs. Br J Gen Pract. 2007;57(535):96-100.

23. van Hassel D, van der Velden L, de Bakker D, Batenburg R. Age-related differences in working hours among male and female GPS: an SMS-based time use study. Human resources for health. 2017;15(1):84.

24. Selmer-Andersen I. Store kjønnsforskjeller i arbeidslivet. Statistics Norway 2018. [https://www.ssb.no/befolkning/artikler-og-publikasjoner/storekjonnsforskjeller-i-arbeidslivet]. Accessed 3 Oct 2020.

25. Rivard MK, Cash RE, Chrzan K, Panchal AR. The impact of working overtime or multiple jobs in emergency medical services. Prehosp Emerg Care. 2019:1-13.

26. Helseforskningsloven (The Health Research Act - ACT 2008-06-20 no.44). [https://lovdata.no/dokument/NL/lov/2008-06-20-44\#KAPITTEL_3] Accessed 03 Oct 2020.

\section{Publisher's Note}

Springer Nature remains neutral with regard to jurisdictional claims in published maps and institutional affiliations.

Ready to submit your research? Choose BMC and benefit from:

- fast, convenient online submission

- thorough peer review by experienced researchers in your field

- rapid publication on acceptance

- support for research data, including large and complex data types

- gold Open Access which fosters wider collaboration and increased citations

- maximum visibility for your research: over $100 \mathrm{M}$ website views per year

At $\mathrm{BMC}$, research is always in progress.

Learn more biomedcentral.com/submission 